\title{
Mobile Stroke Unit in the UK Healthcare System: Avoidance of Unnecessary Accident and Emergency Admissions
}

\author{
Iris Q. Grunwald ${ }^{\mathrm{a}-\mathrm{c}}$ Daniel J. Phillips ${ }^{\mathrm{d}}$ David Sexby ${ }^{\mathrm{d}}$ Viola Wagner $^{\mathrm{e}}$ Martin Lesmeister $^{\mathrm{e}}$ \\ Monika Bachhuber ${ }^{\mathrm{e}}$ Shrey Mathur ${ }^{\mathrm{a}, \mathrm{e}}$ Paul Guyler $^{\mathrm{a}}$ James Fisher $^{\mathrm{a}}$ Saman Perera $^{\mathrm{a}}$ \\ Stefan A. Helwig ${ }^{\mathrm{e}}$ Andrea Schottek ${ }^{\mathrm{e}}$ Ian Ewart ${ }^{\mathrm{a}}$ Nisha Menon ${ }^{\mathrm{a}}$ Muhammad Inam UI Haq ${ }^{\mathrm{a}}$ \\ Daniel Grün ${ }^{\mathrm{e}}$ Fatma Merzou $^{\mathrm{e}}$ Caroline Howard ${ }^{\mathrm{a}}$ Sarah Mapplebeck ${ }^{\mathrm{a}}$ David Dommett $^{\mathrm{a}}$ \\ Sajid Alam ${ }^{f}$ Annie Chakrabarti ${ }^{9}$ Stephen Gerry ${ }^{h}$ Chris Wiltshire ${ }^{d}$ Marcus Bailey ${ }^{d}$ \\ Thomas Bertsch $^{i}$ Theresa Foster ${ }^{d}$ Tom Davis $^{d}$ Wolfgang Reith ${ }^{j}$ Klaus Fassbender $^{\mathrm{e}}$ \\ Silke Walter ${ }^{\mathrm{b}, \mathrm{e}}$ \\ aSouthend University Hospital NHS Foundation Trust, Southend-on-Sea, UK; bepartment of Neuroscience, \\ Medical School, Anglia Ruskin University, Chelmsford, UK; 'Division of Imaging Science and Technology, School \\ of Medicine, University of Dundee, Dundee, UK; ${ }^{d}$ East of England Ambulance Service NHS Trust, Melbourn, UK;

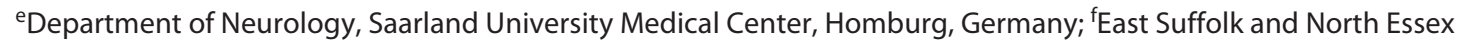 \\ NHS Foundation Trust, Ipswich, UK; ${ }^{9}$ Norfolk and Norwich University Hospital NHS Foundation Trust, Norwich, UK; \\ hInstitute of Medical Statistics, University of Oxford, Oxford, UK; 'Institute of Clinical Chemistry, Laboratory Medicine \\ and Transfusion Medicine, Paracelsus Medical University, Nuremberg, Germany; 'Department of Neuroradiology, \\ Saarland University Medical Center, Homburg, Germany
}

\section{Keywords}

Stroke · Pre-hospital · Mobile stroke unit · Triage $\cdot$ Large vessel occlusion $\cdot$ Thrombolysis

\begin{abstract}
Background: Acute stroke patients are usually transported to the nearest hospital regardless of their required level of care. This can lead to increased pressure on emergency departments and treatment delay. Objective: The aim of the study was to explore the benefit of a mobile stroke unit (MSU) in the UK National Health Service (NHS) for reduction of hospital admissions. Methods: Prospective cohort audit observation with dispatch of the MSU in the East of England Ambulance Service area in Southend-on-Sea was conduct-
\end{abstract}

\section{KARGER}

karger@karger.com www.karger.com/ced
(C) 2020 The Author(s) Published by S. Karger AG, Basel

Karge Open access This is an Open Access article licensed under the Creative Commons Attribution-NonCommercial-4.0 International License (CC BY-NC) (http://www.karger.com/Services/OpenAccessLicense), applicable to the online version of the article only. Usage and distribution for commercial purposes requires written permission. ed. Emergency patients categorized as code stroke and headache were included from June 5, 2018, to December 18,2018 . Rate of avoided admission to the accident and emergency (A\&E) department, rate of admission directly to target ward, and stroke management metrics were assessed. Results: In 116 MSU-treated patients, the following diagnoses were made: acute stroke, $n=33$ (28.4\%); transient ischaemic attacks, $n=13$ (11.2\%); stroke mimics, $n=32$ (27.6\%); and other conditions, $n=38$ (32.8\%). Pre-hospital thrombolysis was administered to 8 of 28 (28.6\%) ischaemic stroke patients. Pre-hospital diagnosis avoided hospital admission for 29 (25.0\%) patients. As hospital treatment was indicated, $35(30.2 \%)$ patients were directly triaged to the stroke unit, 1 patient (0.9\%) even directly to the catheter laboratory. Thus, only 50 (43.1\%) patients required transfer 
to the A\&E department. Moreover, the MSU enabled thrombolysis with a median dispatch-to-needle time of $42 \mathrm{~min}$ (interquartile range, 40-60). Conclusion: This first deployment of an MSU in the UK NHS demonstrated improved triage decision-making for or against hospital admission and admission to the appropriate target ward, thereby reducing pressure on strained A\&E departments.

(C) 2020 The Author(s)

Published by S. Karger AG, Basel

\section{Introduction}

Stroke is the second largest cause of death for persons older than 60 years and contributes to most adult disabilities [1]. In the UK, more than 85,000 patients are admitted annually to hospitals because of new acute stroke [2], and this number is expected to increase by $44 \%$ by 2035 [3].

Unfortunately, most patients arrive at the hospital too late for effective treatment. Only $15-60 \%$ of acute stroke patients arrive at the hospital within $3 \mathrm{~h}$ after the onset of symptoms [4]. This delay dramatically reduces the chances of a good outcome [5] and is an important reason for the observed low rates of thrombolysis $(<12 \%)$ and thrombectomy $(<0.5 \%)[2,6]$.

Acute stroke management is further complicated by a wide spectrum of medical conditions that clinically resemble stroke (stroke mimics), many of which do not warrant hospital admission. Because of insufficient diagnostic tools at the emergency site, it is often impossible to determine whether a patient requires hospital care or, if so, which level of stroke care the target hospital should offer. The default pre-hospital approach tends to be to transfer patients to the nearest accident and emergency (A\&E) department, even though they could have been safely and effectively treated in the community had the diagnosis been known. This fact contributes to the increasing numbers of patients treated in hospital A\&E departments in recent years. It has been reported that a substantial proportion of A\&E department patients could have reasonably been treated by a general practitioner and that approximately $40 \%$ of patients who arrive at an $A \& E$ department are discharged without requiring treatment [7].

The MSU is a specialized ambulance that incorporates a multimodal computed tomography (CT) scanner, a point-of-care (POC) laboratory, and telemedicine communication to the hospital $[8,9]$, in addition to standard ambulance equipment. Studies of pre-hospital stroke management report not only dramatic reductions in delays before thrombolysis [10-13] but also the potential for diagnosis-based triage decision-making [14, 15]. This project aimed to investigate whether an MSU approach for pre-hospital acute stroke diagnosis can help avoid unnecessary A\&E admissions and improve the delivery of rapid recanalizing acute stroke treatment in the UK National Health Service (NHS).

\section{Methods}

\section{Patients and Study Setting}

We conducted this prospective clinical audit (audit number 18034) from June 5, 2018, to December 18, 2018. During this period, the MSU was in service for 62 days. All patients or patient representatives gave written informed consent for participation in this evaluation.

The MSU was stationed at the East of England Ambulance Service NHS Trust (EEAST) emergency medical service (EMS) station in Southend-on-Sea, UK. The MSU operated in a 15-mile radius around the Southend-on-Sea ambulance station. This area is populated by 184,437 inhabitants, $36 \%$ of whom are older than 65 years. The MSU was in operation from 9:00 a.m. to 5:00 p.m., 5 days per week. The EMS dispatcher activated the MSU for acute stroke (dispatch code 28; dispatchers used the Face, Arm, Speech, Time [FAST] questionnaire) or acute severe headache (dispatch code 18). For the first 6 weeks of the study, the MSU was combined with an additional rapid response vehicle; thereafter, it was dispatched alone.

\section{MSU Technology}

The MSU is an ambulance that contains, in addition to standard emergency equipment, the following specialized equipment [10]: (1) an accumulator-driven CT scanner (CereTom, Neurologica/Samsung, Danvers, MA, USA) enabling multimodal imaging; (2) automated image analysis (e-Stroke Suite, Brainomix Ltd., Oxford, UK); (3) a telemedicine system (aycan Digitalsysteme $\mathrm{GmbH}$, Wuerzburg, Germany) enabling videoconferencing and transmission of videos of the patient's examination and of CT scans; and (4) a POC laboratory system for determining full blood count (PocH 100i, Sysmex, Hamburg, Germany), international normalized ratio and activated partial thromboplastin time (Hemochron Elite, ITC, Edison, NY, USA), and creatinine levels (StatSensor, Nova Biomedical, Waltham, MA, USA).

The MSU was staffed with 1 paramedic and 1 stroke physician, and 1 study observer documenting stroke management metrics. In this experimental setting, a radiologist was onboard for the first 50 cases; thereafter, images were analysed remotely by hospital radiologists available via telemedicine.

\section{MSU-Based Stroke Management}

The MSU intervention consisted of a medical history, general clinical and neurological assessment, and POC laboratory tests, and, if clinically indicated, of non-contrast CT studies, and CT angiography and CT perfusion studies. CT angiography was performed if patients had a score of 7 or higher on the National Institutes of Health Stroke Scale (NIHSS), a hyperdense middle cere- 
bral artery sign on a non-contrast CT image, or recurrent symptoms of unknown onset. If indicated, IV thrombolysis (with recombinant tissue plasminogen activator) was administered directly at the emergency site. On the basis of the obtained pre-hospital information, the MSU staff decided whether hospital admission was necessary and, if hospital treatment was required, which target ward would be the most appropriate.

\section{Clinical Assessments}

Assessments included a medical history and general clinical and neurological examinations. All patients were evaluated with the Glasgow Coma Scale (GCS), the modified Rankin Scale (mRS), the NIHSS, and the Los Angeles Motor Scale (LAMS).

\section{Triage Decision Assessment}

Rational triage decision-making was achieved by tabulating the rate of avoided transfers to the hospital's A\&E department. This rate was defined as the sum of cases for which pre-hospital diagnosis allowed either a decision against hospital admission or enabled direct admission to the appropriate ward (stroke unit or catheter laboratory). Triage accuracy was confirmed by a blinded independent rater (an independent $\mathrm{A} \& \mathrm{E}$ physician) who reviewed the pre-hospital and in-hospital documents.

\section{Stroke Management Metrics}

The following stroke management metrics were evaluated: time from 999 emergency call to (1) MSU dispatch and (2) MSU mobile; and time from MSU dispatch to (3) MSU mobile, (4) arrival on scene, (5) first contact to stroke consultant, (6) end of noncontrast CT, (7) end of CT angiography, (8) therapy decision (defined as end of all required diagnostic procedures: neurological examination, POC laboratory testing, and imaging), (9) IV thrombolysis (if indicated), (10) triage decision, (11) end of MSU mission (defined as time of handover to hospital staff), and (12) groin puncture for patients requiring intra-arterial therapy.

\section{Safety Parameters}

The incidence of serious adverse events, including death and stroke-related deterioration (resulting in an increase of at least 4 points in the NIHSS), was documented in the pre-hospital phase and during the hospital stay.

\section{Statistical Analysis}

Stroke management metrics and epidemiological information were expressed as medians (interquartile range) and diagnoses and triage destinations as frequencies (percentage). Only patients with known symptom onset time were taken into account for analysis of symptom onset time metrics.

\section{Results}

\section{Demographic and Clinical Characteristics}

The audit involved 116 patients (66 women, 50 men; median age, 79 years; interquartile range, $65-86$ years) with symptoms of acute stroke or headache. All patients agreed to participate in the audit evaluation. Baseline demographics and clinical characteristics of patients are
Table 1. Medical characteristics, diagnoses, and triage decisions

\begin{tabular}{|c|c|}
\hline Variable & $\begin{array}{l}\text { Patients } \\
(n=116)\end{array}$ \\
\hline \multicolumn{2}{|l|}{ Medical characteristic } \\
\hline Age, years & $79(65-86)$ \\
\hline Female sex & $66(56.9)$ \\
\hline Male sex & $50(43.1)$ \\
\hline Cardiovascular comorbidities & $64(55.2)$ \\
\hline Neurological comorbidities & $62(53.4)$ \\
\hline Previous cerebral infarction & $14(22.2)$ \\
\hline $\mathrm{GCS}^{\mathrm{a}}$ & $15(14-15)$ \\
\hline NIHSS score $e^{b}$ & $6(4-7.25)$ \\
\hline Pre-mRS & $1(0-3)$ \\
\hline $\mathrm{mRS}^{\mathrm{b}}$ & $4(3-4)$ \\
\hline mRS discharge $\mathrm{e}^{\mathrm{b}}$ & $3(2-4)$ \\
\hline LAMS $^{\mathrm{b}}$ & $3(1-3)$ \\
\hline \multicolumn{2}{|l|}{ Diagnosis } \\
\hline Ischaemic stroke & $28(24.1)$ \\
\hline Intracranial haemorrhage & $5(4.3)$ \\
\hline TIA & $13(11.2)$ \\
\hline Stroke mimics & $32(27.6)$ \\
\hline Other conditions & $38(32.8)$ \\
\hline \multicolumn{2}{|l|}{ Triage destination } \\
\hline $\mathrm{A} \& \mathrm{E}^{\mathrm{c}}$ & $50(43)$ \\
\hline Stroke unit & $35(30)$ \\
\hline Catheter laboratory & $1(1)$ \\
\hline Left at ambulatory setting & $29(25)$ \\
\hline Including TIA clinic referrals & $2(2)$ \\
\hline $\begin{array}{l}\text { Air-lifted directly to comprehensive centre } \\
\text { without MSU assessment on scene }\end{array}$ & $1(1)$ \\
\hline
\end{tabular}

Medical characteristics are presented as median (interquartile range) and sex, comorbidities, diagnosis, and triage destination data as frequency (percentage). A\&E, accident and emergency; GCS, Glasgow Coma Scale; LAMS, Los Angeles Motor Scale; mRS, modified Rankin Scale; MSU, mobile stroke unit; NIHSS, National Institutes of Health Stroke Scale; TIA, transient ischaemic attack. a All patients. b Only stroke patients. c Including 5 patients initially triaged to a stroke unit but who had to be transferred to $A \& E$ due to transient shortage of beds on the stroke unit.

presented in Table 1. Four representative cases are described in Figure 1.

\section{MSU Triage Decisions}

On the basis of pre-hospital diagnosis, 29 patients (25.0\%) were effectively treated in the pre-hospital setting rather than being transported to the hospital. The diagnostic groups and their triage pathways are presented in Figure 2.

Moreover, when hospital-based treatment was indicated, aetiology-based transport to a specialized ward (stroke unit, catheter laboratory, or transient ischaemic 
Fig. 1. Exemplary cases of MSU deployment in the UK healthcare system. a A patient (female, 82 years old) with right-sided sensorimotor paresis and severe dysphasia (NIHSS 7) seen more than $3 \mathrm{~h}$ after onset. After pre-hospital diagnosis including CT, thrombolysis was administered directly at the emergency site. b A patient (female, 51 years old) with thunderclap headache and nausea (NIHSS 1). Pre-hospital imaging enabled the diagnosis of SAH at the emergency site. The nearest neurovascular centre was pre-notified. c A patient (male, 89 years old) with severe sensorimotor hemiparesis (NIHSS 16). Pre-hospital vascular imaging revealed LVO (white arrow) as the basis for direct transfer to the catheter laboratory, thus bypassing the A\&E Department. d A patient (male, 73 years old) for whom pre-hospital diagnosis of a stroke mimic (Bell's palsy) allowed for a triage decision against hospital admission, and for phoning the patient's general practitioner for oral steroid treatment in the pre-hospital setting. NIHSS, National Institutes of Health Stroke Scale; SAH, subarachnoid haemorrhage; LVO, large vessel occlusion; MSU, mobile stroke unit; CT, computed tomography; A\&E, accident and emergency.
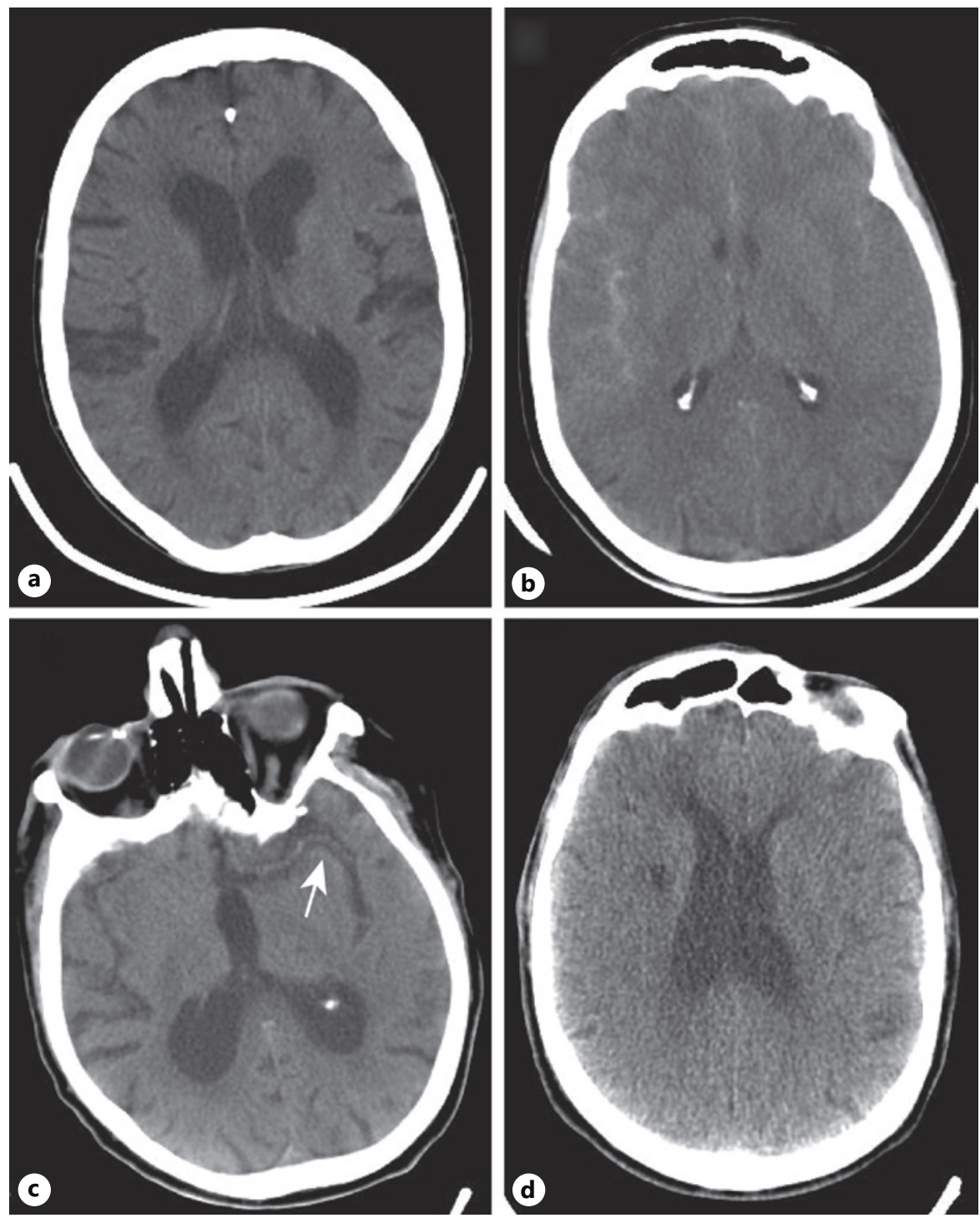

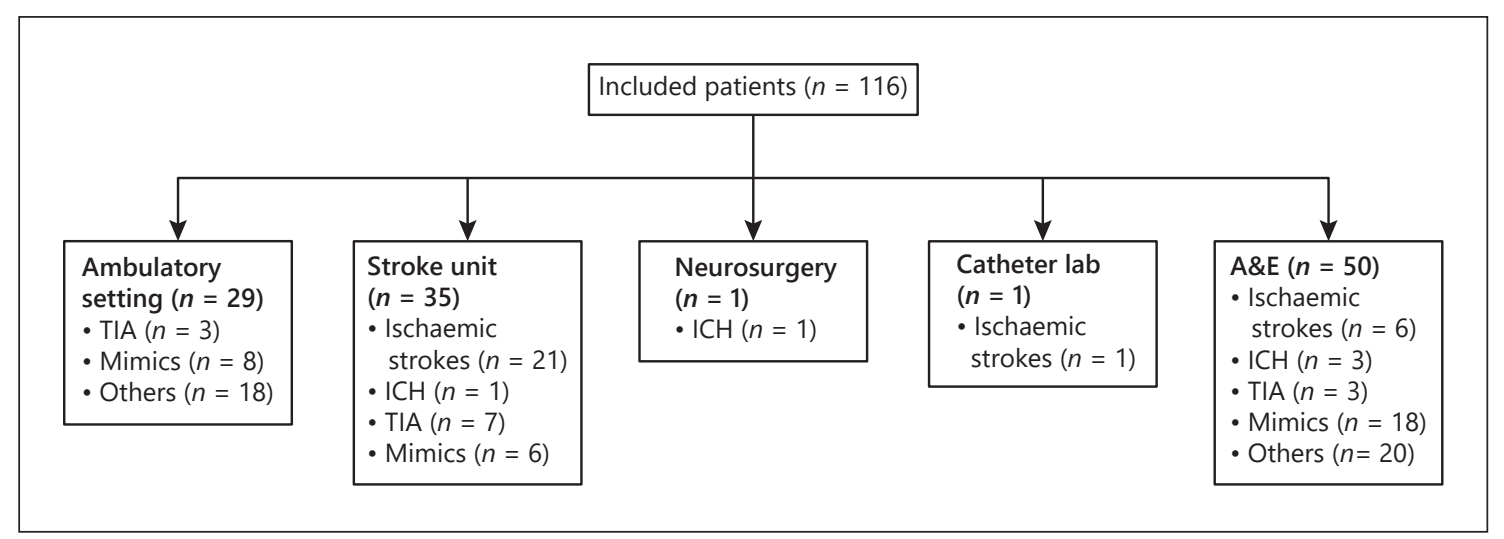

Fig. 2. Flowchart of included patients. A\&E, accident and emergency; ICH, intracranial haemorrhage; TIA, transient ischaemic attack. 
Table 2. Stroke management metrics (median, interquartile range)

\begin{tabular}{|c|c|c|c|}
\hline Variable, min & $\begin{array}{l}\text { MSU } \\
(n=116)\end{array}$ & National $^{\mathrm{a}}$ & $\begin{array}{l}\text { Southend- } \\
\text { on-Sea }^{\text {a }}\end{array}$ \\
\hline Symptom onset to 999 call & $50(8-172)$ & & \\
\hline Emergency 999 call to MSU dispatch & $7(4-15)$ & & \\
\hline Symptom onset to MSU dispatch (MSU call) & $61(21-188)$ & & \\
\hline MSU dispatch (MSU call) to MSU mobile (start of mission) & $2(0-3)$ & & \\
\hline Emergency 999 call to MSU mobile & $10(6-18)$ & & \\
\hline MSU dispatch to on-scene arrival & $13(11-18)$ & & \\
\hline Symptom onset to on-scene arrival & $78(35-203)$ & & \\
\hline Distance covered, $\mathrm{km}$ & $10.4(6.3-19.3)$ & & \\
\hline MSU dispatch to first contact to MSU consultant & $15(12-18)$ & & \\
\hline Door to first contact to stroke consultant (in person) & & 616 & 578 \\
\hline MSU dispatch to end of non-contrast CT & $46(39-53)$ & & \\
\hline MSU dispatch to end of non-contrast $\mathrm{CT}^{\mathrm{b}}$ & $37(35-51)$ & & \\
\hline MSU dispatch to end of CT-angiography & $60(56-64) ; n=10$ & & \\
\hline MSU dispatch to therapy decision ${ }^{\mathrm{c}}$ & $36(23-50)$ & & \\
\hline MSU dispatch to therapy decision ${ }^{\mathrm{b}, \mathrm{c}}$ & $38(36-53)$ & & \\
\hline MSU dispatch to needle ${ }^{b}$ & $42(40-60) ; n=8$ & & \\
\hline Hospital door to needle & & 50 & 75 \\
\hline MSU dispatch to triage decision & $41(28-55)$ & & \\
\hline MSU arrival on scene to end of non-contrast CT & $31(26-35)$ & & \\
\hline MSU arrival on scene to end of non-contrast $\mathrm{CT}^{\mathrm{b}}$ & $30(21-35)$ & & \\
\hline MSU arrival on scene to therapy decision ${ }^{c}$ & $21(21-33)$ & & \\
\hline MSU arrival to therapy decision ${ }^{\mathrm{b}, \mathrm{c}}$ & $31(21-38)$ & & \\
\hline MSU arrival to needle $\mathrm{b}^{\mathrm{b}}$ & $33(26-45)$ & & \\
\hline Onset to needle & $115(100-189)$ & 146 & 155 \\
\hline On-scene duration & $45(38-59)$ & & \\
\hline Emergency 999 call to hospital door & & 65 & 65 \\
\hline MSU dispatch to groin puncture & $122 ; n=1$ & & \\
\hline MSU dispatch to end of mission (handover at hospital) & $81(68-102)$ & & \\
\hline
\end{tabular}

Data are displayed as median (interquartile range), unless otherwise noted. ${ }^{a}$ Register data from July to December 2018 (audit data SSNAP and EEAST). ${ }^{\mathrm{b}}$ Only tPA patients. ${ }^{\mathrm{c}}$ Defined as end of diagnostic workup with clinical examination, CT scan, and laboratory as indicated.

attack [TIA] clinic) was accomplished for $38(32.8 \%)$ patients: 35 patients $(30.2 \%)$ were taken to a stroke unit, 1 patient $(0.9 \%)$ was taken to a catheter laboratory, and 2 patients $(1.7 \%)$ were taken to a TIA clinic. These patients were directly handed over from the EMS personnel to the specialists in the target ward or were left at home when referral to a TIA clinic was required. One patient (0.9\%) did not undergo MSU assessment because of clinical instability; this patient required direct air transportation to a comprehensive centre nearest to the emergency site.

A triage decision for transport to an A\&E department was made for $45(38.8 \%)$ patients (Table 1). For an additional 5 (4.3\%) stroke patients, despite pre-hospital diagnosis and pre-notification of the stroke unit, a planned direct transfer to that unit could not be realized because of unavailability of beds at that time. Thus, the overall number of patients transferred to an A\&E department was $50(43.1 \%)$. The diagnosis of the non-stroke patients and their triage destination is detailed in online suppl. Table 1; see www.karger.com/doi/10.1159/000508910.

Comparison of triage decisions by the MSU team and those of the blinded independent A\&E physician rater showed that this rater would have left $3(2.6 \%)$ more patients at home than the MSU team did. Importantly, the MSU team left no patient at home who was judged by the rater to require hospital treatment. The independent rater would have triaged 5 more patients to the stroke unit (4.3\%; 3 with intracranial haemorrhage or subarachnoid haemorrhage). The MSU team transferred these patients to the $A \& E$ resuscitation area that offered a higher level of care instead. The rater would have directly triaged 1 
stroke mimic (0.9\%) to the A\&E department, whereas the MSU team triaged this patient to the stroke unit.

Regarding the number of CTs required to differentiate stroke mimics and other conditions from stroke, noncontrast CT was performed for 22 of 32 stroke mimics and for 6 of 38 other medical conditions, and CT angiography was performed for 4 stroke mimics. All other nonstroke patients were diagnosed by clinical examination and POC laboratory.

\section{Stroke Management Metrics}

MSU-based stroke management metrics are shown in Table 2. The thrombolysis rate for patients with acute ischaemic stroke was 29\%. Median times from MSU dispatch-to-needle of $42 \mathrm{~min}$ (40-60 $\mathrm{min}$ ) were achieved. These times compare favourably with door-to-needle times regionally and nationwide (Table 2). Similar benefits were observed in the other stroke management metrics (Table 2). Amongst patients who obtained thrombolysis, the EMS was alerted a median of 66 min (46-141 min) after symptom onset; thus, the time of the alert was often already past the first "golden" hour time window.

\section{Short-Term Outcomes and Safety}

The mRS of stroke patients at discharge was 3 (2-4) (Table 1). No complications occurred in the pre-hospital phase of acute stroke management. No patient who received IV thrombolysis in the MSU experienced complications with bleeding. In the hospital, 1 patient $(0.9 \%)$ died of stroke-related causes: this patient experienced severe subarachnoid haemorrhage related to anticoagulation treatment. Five patients $(4.3 \%)$ died of causes not related to stroke.

\section{Discussion}

This study showed that MSU-based stroke management allowed to avoid hospital A\&E admissions. This was accomplished by pre-hospital triage decision-making against hospital admissions in $25 \%$ of the patients and direct admission to the required specialized target ward. In fact, $30 \%$ of the patients were directly taken to the stroke unit and 1 patient with large vessel occlusion even directly to the catheter laboratory for intra-arterial therapy. Thus, in total, admission to the hospital's A\&E department was avoided for $55 \%$ of the patients.

The role of MSUs in pre-hospital triage decision-making may be relevant because unnecessary hospital admissions are not only expensive but may also be associated

Mobile Stroke Unit in the UK Healthcare System with adverse medical consequences, such as an increased risk of delirium, depression, poor quality of life, healthcare-acquired infections, and falls. This finding is in line with estimates showing that approximately one-fifth to one-third of admissions of frail and elderly patients could be avoided by an early review by a qualified clinical decision-maker [16].

Moreover, MSU-based stroke management enabled ultra-early thrombolysis with an MSU dispatch-to-needle time of $42 \mathrm{~min}$ and a thrombolysis rate of $29 \%$, which is higher than the national UK average of $11-12 \%$. The observed times to treatment are amongst the fastest reported times to treatment in clinical studies and registries to date [17]. This call-to-needle time compares favourably even with in-hospital mean door (of the hospital)-toneedle times of $50 \mathrm{~min}$ at a national level [18]. This reduction in delay can be explained by both the reduced transport times and the increased efficiency between the various groups of healthcare professionals involved in the complex stroke rescue chain. However, the finding of a relevant delay before EMS alert in most patients underlines the necessity of public awareness campaigns for stroke in this region. Safety endpoints were comparable to those of other studies investigating MSUs $[10,11]$.

The main indication for deploying the MSU was acute stroke. Stroke mimics and other conditions could be differentiated at the emergency site, and differential triage to the most appropriate target destination was possible. Conditions other than stroke were treated conventionally; in this case, the MSU functioned as a normal ambulance.

A limitation of this study is that patients were not randomly assigned to a control group because of the audit format of this intervention. Besides, the study population was relatively small. Therefore, additional research is necessary for assessing clinical benefits with long-term follow-up data.

A current problem for efficient use of MSUs is the suboptimal dispatch accuracy for stroke in general, which means that the MSU team sees a high percentage of nonstroke cases. Indeed, poor accuracy of the detection of stroke in the EMS dispatch office is increasingly being recognized, and sensitivities ranging between 41 and $73 \%$ have recently been reported in a meta-analysis of 5 large studies [19].

Current efforts aimed at reducing the number of false dispatches include improving the training of healthcare personnel at the dispatch location, improving dispatch algorithms, and using scales for stroke recognition. Other approaches currently being explored are pre-evaluation 
of patients by the first arriving EMS team and cancellation of MSU dispatch when the absence of stroke has been determined [20]. More research is needed to optimize dispatch accuracy.

In the future, the cost-effectiveness of the MSU may be improved by substituting on-board physicians by telemedicine-linked remote experts. Health economic analysis in the NHS context is necessary. In conclusion, this first experience in the UK healthcare system demonstrates that, apart from enabling ultra-early thrombolysis, this approach allows for accurate triage decisions at the emergency site, thereby reducing unnecessary admissions to currently strained $A \& E$ departments.

\section{Acknowledgements}

We are very grateful for the excellent paramedic support from $\mathrm{Lu}$ Harrington and Michael Foster. Many thanks go to Emma Green, Hope Grey, Robert Honeybourne, and Gregory Keshishian for technical support with laboratory and radiological devices. We thank Sam James, Mark Hellenbrand, and Neil Rothnie for administrative support of the project. We express our gratitude to Fred Heddell for his tireless support in communication with charities and the public, and for all of his additional support. We very much appreciate the support of Julie Gooding and the patient representative group involved in this project. Their input and feedback gave us important information about public awareness and opinion on an MSU in pre-hospital care in the UK.

\section{Statement of Ethics}

The evaluation was conducted as a clinical audit. The aim was to improve the quality of stroke management. It involved comparing the effectiveness of MSU stroke management with the agreedupon and proven standard pathway. The project was not designed as a randomized clinical trial. Before the project began, it was registered as an audit (audit number: 18034) by the Southend University NHS Foundation Trust Audit Department. In line with the National Ethics Regulation, no ethical approval was obtained for this audit.

\section{Conflict of Interest Statement}

Iris Q. Grunwald is cofounder and chairholder of Brainomix Ltd., Oxford. No conflicts with this manuscript exist. No other author has reported a conflict of interest; that is, no author has received support from any organization for the submission of this work, has held any financial relationship with any organization that might have an interest in the submitted work, or has other relationships or activities that could appear to have influenced the submitted work.

\section{Funding Sources}

The evaluation was funded by the ASET Charity and Southend University Hospital Charitable Trust. The researchers were totally independent of funding sources. All authors had full access to all of the data in the study and take responsibility for the integrity of the data and the accuracy of the data analysis.

\section{Author Contributions}

Iris Q. Grunwald, Daniel Phillips, David Sexby, Paul Guyler, and Klaus Fassbender conceived the study and took part in its administration. Iris Q. Grunwald and James Fisher acquired funding and took part in project administration. Iris Q. Grunwald, Daniel Phillips, David Sexby, Paul Guyler, James Fisher, Chris Wiltshire, Marcus Bailey, Theresa Foster, Tom Davis, and Klaus Fassbender provided resources. Iris Q. Grunwald, Daniel Phillips, David Sexby, Martin Lesmeister, Paul Guyler, Andrea Schottek, Sarah Mapplebeck, David Dommett, Chris Wiltshire, Marcus Bailey, Thomas Bertsch, Theresa Foster, Tom Davis, and Klaus Fassbender designed the methodology. Iris Q. Grunwald, Daniel Phillips, David Sexby, Viola Wagner, Saman Perera, Stefan A. Helwig, Ian Ewart, Nisha Menon, Muhammad Inam Ul Haq, Caroline Howard, Sajid Alam, Annie Chakrabarti, and Silke Walter took part in the investigation itself. Iris Q. Grunwald, Daniel Phillips, David Sexby, Monika Bachhuber, Shrey Mathur, Sarah Mapplebeck, David Dommett, Stephen Gerry, Thomas Bertsch, Klaus Fassbender, and Silke Walter took part in validation. Iris Q. Grunwald, Daniel Phillips, David Sexby, Paul Guyler, James Fisher, Sarah Mapplebeck, David Dommett, Chris Wiltshire, Marcus Bailey, Thomas Bertsch, Theresa Foster, Tom Davis, Wolfgang Reith, Klaus Fassbender, and Silke Walter took part in supervision of the project. Iris Q. Grunwald, Daniel Phillips, Viola Wagner, Martin Lesmeister, Monika Bachhuber, and Silke Walter secured data curation. Martin Lesmeister and Monika Bachhuber were responsible for provision of software. Daniel Grün and Fatma Merzou worked on visualization. Iris Q. Grunwald, Daniel Phillips, Viola Wagner, Martin Lesmeister, Shrey Mathur, Klaus Fassbender, and Silke Walter performed formal analysis. Viola Wagner, Martin Lesmeister, Shrey Mathur, Klaus Fassbender, and Silke Walter wrote the original draft, while all authors were involved in textual review and editing as well.

\section{Availability of Data and Material}

Data are available upon reasonable request to the corresponding author Klaus Fassbender: klaus.fassbender@uks.eu. No additional unpublished data are available.

\section{Transparency Declaration}

The lead author Klaus Fassbender (corresponding author) confirms that the manuscript is an honest, accurate, and transparent account of the reported study. He confirms that no important aspects of the study have been omitted. 


\section{References}

$1 \mathrm{Xu}$ XM, Vestesson E, Paley L, Desikan A, Wonderling D, Hoffman A, et al. The economic burden of stroke care in England, Wales and Northern Ireland: using a national stroke register to estimate and report patientlevel health economic outcomes in stroke. Eur Stroke J. 2018 Mar;3(1):82-91.

2 Aguiar de Sousa D, von Martial R, Abilleira S, Gattringer T, Kobayashi A, Gallofré M, et al. Access to and delivery of acute ischaemic stroke treatments: a survey of national scientific societies and stroke experts in 44 European countries. Eur Stroke J. 2019 Mar;4(1): 13-28.

3 Stevens E, Emmett E, Wang Y, McKevitt C, Wolfe C. The Burden of Stroke in Europe: the challenge for policy makers. Stroke Alliance for Europe, 2017 [cited 2019 Oct 29]. Available from: https://www.stroke.org.uk/sites/ default/files/the_burden_of_stroke_in_europe_-_challenges_for_policy_makers.pdf.

4 Evenson KR, Foraker RE, Morris DL, Rosamond WD. A comprehensive review of prehospital and in-hospital delay times in acute stroke care. Int J Stroke. 2009 Jun;4(3):187_ 99.

5 Froehler M, Saver J, Zaidat O, Jahan R, AzizSultan M, Klucznik R, et al. Interhospital transfer before thrombectomy is associated with delayed treatment and worse outcome in the STRATIS registry (systematic evaluation of patients treated with neurothrombectomy devices for acute ischemic stroke). Circulation. 2017 Dec;136(24):2311-21.

6 McMeekin P, White P, James MA, Price CI, Flynn D, Ford GA. Estimating the number of UK stroke patients eligible for endovascular thrombectomy. Eur Stroke J. 2017 Dec;2(4): 319-26.
7 O’Keeffe C, Mason S, Jacques R, Nicholl J. Characterising non-urgent users of the emergency department (ED): a retrospective analysis of routine ED data. PLoS One. 2018 Feb; 13(2):e0192855.

8 Fassbender K, Walter S, Liu Y, Muehlhauser F, Ragoschke A, Kuehl S, et al. "Mobile stroke unit" for hyperacute stroke treatment. Stroke. 2003 Jun;34(6):e44.

9 Walter S, Kostpopoulos P, Haass A, Helwig S, Keller I, Licina T, et al. Bringing the hospital to the patient: first treatment of stroke patients at the emergency site. PLoS One. 2010 Oct;5(10):e13758.

10 Walter S, Kostopoulos P, Haass A, Keller I, Lesmeister M, Schlechtriemen T, et al. Diagnosis and treatment of patients with stroke in a mobile stroke unit versus in hospital: a randomised controlled trial. Lancet Neurol. 2012 May;11(5):397-404.

11 Ebinger M, Winter B, Wendt M, Weber JE, Waldschmidt C, Rozanski M, et al. Effect of the use of ambulance-based thrombolysis on time to thrombolysis in acute ischemic stroke: a randomized clinical trial. JAMA. 2014 Apr; 311(16):1622-31

12 Parker SA, Bowry R, Wu TC, Noser EA, Jackson $\mathrm{K}$, Richardson L, et al. Establishing the first mobile stroke unit in the United States. Stroke. 2015 May;46(5):1384-91.

13 Itrat A, Taqui A, Cerejo R, Briggs F, Cho SM, Organek N, et al. Telemedicine in prehospital stroke evaluation and thrombolysis: taking stroke treatment to the doorstep. JAMA Neurol. 2016 Feb;73(2):162-8.

14 Kostopoulos P, Walter S, Haass A, Papanagiotou P, Roth C, Yilmaz U, et al. Mobile stroke unit for diagnosis-based triage of persons with suspected stroke. Neurology. 2012 Jun; 78(23):1849-52.
15 Helwig S, Ragoschke-Schumm A, Schwindling L, Kettner M, Roumia S, Kulikovski J, et al. Prehospital stroke management optimized by use of clinical scoring vs mobile stroke unit for triage of patients with stroke: a randomized clinical trial. JAMA Neurol. 2019 Dec; 76(12):1484-92.

16 Mytton OT, Oliver D, Mirza N, Lippett J, Chatterjee A, Ramcharitar K, et al. Avoidable acute hospital admissions in older people. $\mathrm{Br}$ J Healthc Management. 2012 Aug;18(11): 597-603.

17 Fassbender K, Balucani C, Walter S, Levine SR, Haass A, Grotta J. Streamlining of prehospital stroke management: the golden hour. Lancet Neurol. 2013 Jun;12(6):585-96.

18 Sentinel Stroke National Audit Program (SS NAP), School of Population Health and Environmental Sciences, King's College London on behalf of the Intercollegiate Stroke Working Party [Internet]. SSNAP Annual Public Report 2018, King's College London 2019 [cited 2019 Oct 29]. Available from: https:// www.strokeaudit.org/Documents/National/ Clinical/Apr2017Mar2018/Apr2017Mar2018-AnnualReport.aspx.

19 Oostema JA, Carle T, Talia N, Reeves M. Dispatcher stroke recognition using a stroke screening tool: a systematic review. Cerebrovasc Dis. 2016 Dec;42(5-6):370-7.

20 Zhao H, Coote S, Easton D, Langenberg F, Stephenson M, Smith K, et al. Melbourne mobile stroke unit and reperfusion therapy: greater clinical impact of thrombectomy than thrombolysis. Stroke. 2020 Mar;51(3):92230. 